\title{
Uso juicioso de antibióticos en otitis media
}

\author{
"Otitis Media-Principles of Judicious Use of Antimicrobial Agents"
}

Marcy S, Philips W. Pediatrics Suplement Jan 1998;165-171.

\section{Objetivo}

Discriminar las otitis medias que requieren antibióticos de las que no los requieren, para evitar el uso innecesario de los mismos.

\section{Diseño}

Guía de práctica clínica respaldada por evidencia científica y con revisión de pares. Fue consensuada entre miembros del Centro de Control de las Enfermedades de E.U. (CDC), la Academia Americana de Pediatría y la Academia Americana de Medicina Familiar.

\section{Fuente de los datos}

Medline entre 1966 y 1996. Se buscaron artículos en inglés y los resultados fueron complementados con revisiones, citas de capítulos de libros y publicaciones de simposios. Se excluyeron resúmenes y trabajos no publicados.

\section{Selección de los estudios}

Se le dio prioridad a la información obtenida por trabajos controlados, aleatorizados, que incluyeran grupo placebo, que tuvieran criterios estrictos de diagnóstico o confirmación bacteriológica y que hubieran sido realizados en población pediátrica. Sin embargo, en algunas instancias que se mencionan específicamente, se consideraron trabajos de población adulta, trabajos con número pequeño de pacientes o trabajos descriptivos.

\section{COMENTARIO}

Como dicen los autores, a pesar de que ya se conoce que la historia natural de la OMA tratada apropiadamente puede incluir derrame por varias semanas, se sigue tratando con antibióticos a niños con derrames asintomáticos encontrados incidentalmente con las consecuencias ecológicas y económicas derivadas de la presión de los antibióticos sobre los gérmenes.(1-2)

Si bien teóricamente el diagnóstico de 0MA no debería ofrecer inconvenientes, la práctica clínica plantea algunas dificultades que pueden llevar a cometer errores. Un consenso reciente sobre infecciones en pediatría ambulatoria elaborado por la Sociedad Argentina de Pediatría enumera las principales razones que explican los diagnósticos incorrectos de OMA: Inadecuada visualización del tímpano por descamación del conducto auditivo u obstrucción con cerumen, otoscopio con mala luz, escasa experiencia del observador, llanto del niño durante el examen y escasa práctica con la otoscopía neumática. (4) También es probable que aún teniendo dudas del diagnóstico, los médicos se dejen convencer por la ansiedad de los padres indicando antibióticos en situaciones en las cuales sería más adecuado adoptar una conducta expectante.

No sólo existen las dificultades semiológicas planteadas previamente que seguramente nos resultan conocidas, sino que además hay mucha discrepancia entre los distintos médicos en cuanto a la constelación de signos y síntomas requeridos para definir a la OMA. Respecto de éste último punto, los autores eligen una definición de OMA muy estricta que requiere como condición indispensable la presencia de derrame en el oído medio, más signos locales o sistémicos de enfermedad aguda. Usando esta definición podemos estar seguros de que evitaremos tratamientos antibióticos innecesarios. Sin embargo, es posible que privemos de tratamiento a algunos niños que podrían llegar a beneficiarse con el mismo, especialmente si tenemos en cuenta que en nuestro medio está muy poco difundido el uso de la otoscopía neumática. Los autores de esta guía sostienen que en pacientes con OMA la evidencia acumulada mediante trabajos controlados y aleatorizados es a favor del uso de antibióticos, siendo pequeño el efecto atribuible al tra-

\section{Datos principales}

Según los autores la otitis media debe clasificarse como otitis media aguda (OMA) u otitis serosa (OS). Ambas requieren para su diagnóstico de la presencia de derrame en el oído medio. Lo que las diferencia es la presencia de signos de enfermedad aguda local o sistémica para la OMA y de su ausencia para la OS.

Derrame: Se debe usar otoscopía neumática para explorar el color, la posición, la transparencia y la movilidad de la membrana. Raramente se pueden observar signos de inflamación aguda horas antes de la aparición del derrame.

Signos locales de enfermedad aguda: Otalgia u otorrea provenientes del oído medio. Membrana abombada, opaca o con líquido amarillo por detrás de la misma, o claramente roja. El dolor de oído es muy específico. No debe atribuirse a OMA el hecho de que el niño se tire de la oreja en ausencia de otros criterios.

Signos sistémicos de enfermedad aguda: La fiebre puede ser indicativa de OMA, pero en ausencia de signos locales de inflamación, a menudo no tiene relación con el derrame encontrado en el oído medio. Puede haber rinorrea, tos, irritabilidad, cefalea, anorexia, vómitos y diarrea pero no son específicos de OMA. Los catarros de

tamiento ya que el $95 \%$ de los pacientes tratados con antibióticos tienen resolución clínica en 7 a 14 días contra el $80 \%$ de los no tratados. Del Mar y col, en un reciente metanálisis no encontraron diferencias a las $24 \mathrm{~h}$ de tratamiento, ni efecto para prevenir la recurrencia de la enfermedad, pero sí encontraron una disminución del dolor entre el segundo y el séptimo día(10\% vs 14,3\%), una reducción en la aparición de OMA contralateral ( $10 \%$ vs $16,6 \%$ ) y de sordera a los 3 meses $(13,3 \%$ vs $19,7 \%)$ atribuibles al tratamiento antibiótico (3).

En los últimos tiempos han apareciendo varios trabajos que ponen en duda la utilidad del uso de antibióticos en las otitis medias agudas (1). Más aún, en Holanda se ha desarrollado en 1990 una guía para el manejo de la OMA que recomienda tratar sintomáticamente sin antibióticos a los niños mayores de seis meses hasta reevaluarlos. En niños con edad entre seis meses y dos años dicha reevaluación debe ser hecha a las 24 horas de comenzado el cuadro y en los mayores de dos años puede diferirse hasta los tres días. En caso de no haber mejoría del cuadro en dicho lapso recomiendan comenzar con antibióticos siendo de primera elección la amoxicilina (1).

Quienes están a favor del uso de antibióticos argumentan que en la era pre-antibiótica era muy común la aparición de complicaciones intracraneales graves $(3 \%)$, las cuales se han vuelto muy infrecuentes $(0,15 \%)$ en nuestros días de uso de antibióticos (5). También se sugiere que este fenómeno podría deberse a que en la era pre-antibiótica muchas otitis no llegaban a dignosticarse y se curaban sin recibir atención médica. De este modo había más probabilidades de que las otitis medias agudas que se dignosticaran fueran las más graves, simulando una tasa falsamente más alta de complicaciones que en la actualidad.

Hay que recordar que la mayoría de los trabajos que ponen en duda la utilidad del tratamiento inicial de la OMA con antibióticos provienen de países desarrollados. Por lo tanto hay que ser muy cuidadoso antes de trasladar las conclusiones de los mismos a nuestro medio. En los países subdesarrollados se tiene un umbral más bajo para indicar tratamientos antibióticos. Una de las razones de esta conducta es el te- 
vía aérea superior habitualmente preceden a la OMA, pero no hacen diagnóstico.

Otitis media aguda: La OMA no complicada en mayores de 2 años, sin comorbilidades y sin recurrencias puede ser tratada con 5 a 7 días de antibióticos. Hay buena evidencia para el tratamiento con cefuroxima por 5 días y con monodosis de ceftriaxone.

Algunos autores recomiendan observación y analgésicos por 48 horas. Sólo indican antibióticos ante la persistencia del cuadro luego de ese lapso. Utilizando esta estrategia, la tasa de curación es de un $66-92 \%$.

Es esperable encontrar derrame en el oído medio luego de una OMA correctamente tratada. En 70\% de los pacientes persiste dos semanas, en $50 \%$ un mes, en $20 \%$ dos meses y en $10 \%$ tres meses. Éstos pacientes no deben recibir antibióticos.

Otitis serosa: Los metanálisis mostraron una diferencia estadísticamente significativa sólo en la resolución a corto plazo a favor del uso de antibióticos (NNT=7), sin diferencias al mes de tratamiento. Como el $65 \%$ de las 0 S y el $90 \%$ de los derrames consecutivos a OMA resuelven espontáneamente en 3 meses, no se recomienda usar antibióticos (exceptuando a las OS bilaterales con pérdida de la audición, siendo alternativos a la miringotomía bilateral con inserción de tubos).

Fuente de Financiamiento: No referida.

mor de no poder volver a controlar a los pacientes debido a que la accesibilidad a nuestros sistemas de salud no es la óptima. Nuestro país no es una excepción a esta regla y por el momento la Sociedad Argentina de Pediatría recomienda tratar con antibióticos desde el inicio a los pacientes con OMA.

A la hora de elegir el antibiótico, cabe mencionar que en varios hospitales de Buenos Aires, la etiología bacteriana de la OMA oscila entre el $49 \%$ y el $70 \%$. Predomina el S. pneumoiae ( 34 al $50 \%$ de las punciones con desarrollo bacteriano), seguido por el $\mathrm{H}$. Influenzae (30 al 43\%), y en menor medida el S. aureus ( 4 al $7 \%$ ) y la $\mathrm{M}$. catarralis ( 2 al $6,5 \%$ ). Respecto de los S. pneumoiae se puede decir que son ampliamente sensibles a la penicilina, siendo la resistencia a los de los $\mathrm{H}$. influenzae de un $16 \%$ para la trimetoprima-sulfametoxazol y entre un 9 y $17 \%$ para los ß-lactámicos según las series (4). En nuestro medio, se prefiere la amoxicilina a $40-50 \mathrm{mg} / \mathrm{kg} / 24 \mathrm{~h}$ dividida en tres dosis durante diez días, sin embargo pareciera que tratamientos más cortos podrían ser iqualmente efectivos. En pocos años es probable que deje de ser el antibiótico de elección para el tratamiento empírico inicial de la OMA, debido al incremento creciente de la resistencia a los ß-lactámicos siendo reemplazada por las cefalosporinas de segunda generación. En cuanto a la estrategia de vacunación con vacuna anti influenza que recomiendan los autores para prevenir la recurrencia de OMA, se basan en un trabajo finlandés (6) en el cual se demostró una disminu-
Profilaxis antibiótica para la OMA recurrente: Los antibióticos en bajas dosis disminuyen la recurrencia de OMA en 1,31 episodios por paciente por año. Deben indicarse por seis meses o menos ante 3 o más episodios documentados de OMA en los últimos 6 meses 04 en el último año. Los tratamientos más largos son menos efectivos y aumentan la portación de cepas resistentes. Se prefiere el sulfisoxazol a la amoxicilina, ya que aquel tiene menor probabilidad de promover colonización con gérmenes productores de b-lactamasa o de neumococos resistentes. Los que más se benefícian son los menores de 2 años y los que asisten a guarderías. Se recomienda la eliminación del hábito de fumar en la casa, del chupete, la reducción del tiempo en las guarderías y la vacunación anti-influenza.

ción de la incidencia de OMA atribuible a la vacunación del 7 \%. Hay que tener en cuenta que la vacunación de los participantes de este trabajo se implementó previamente a una epidemia de Influenza A en dicha región y que aún así fue necesario vacunar a 14 niños para evitar un episodio de 0MA. Por el momento, no parece adecuado concluir que se deba indicar vacuna anti influenza ante todo niño con otitis medias agudas recurrentes.

Recientemente, se ha publicado un trabajo realizado en niños sanos, en el cual se evaluó la eficacia de una vacuna intranasal trivalente contra influenza, hallándose que por cada 17 niños vacunados se previno un episodio de OMA(7). (Este artículo será comentado en los próximos números de esta revista.)

Para resumir, podemos decir que es creciente la controversia acerca de la utilidad de los antibióticos en el manejo inicial de la OMA; que las guías extranjeras desarrolladas en el primer mundo avalan el manejo expectante de la OMA con buenos resultados; que por el momento no es fácil trasladar sus conclusiones a nuestra práctica; y que en nuestro medio los antibióticos todavía siguen siendo el tratamiento recomendado para el manejo inicial de la OMA.

Si bien puede ser discutible, no sería descabellado intentar una primera etapa de tratamiento conservador en pacientes mayores de dos años, previamente sanos, de buen medio socioeconómico, con fácil acceso a los servicios médicos y con padres con buen nivel de alarma.

Dr. Sergio A. Terrasa

Unidad de Medicina Familiar y Preventiva Hospital Italiano de Buenos Aires.

\section{Referencias}

1. Froom J, Culpepper, Jacobs M, et al. Antimicrobials for acute otitis media? A review from the international primary care network. BMJ 1997: 315:98-102 2. Hart A. Antibiotic resistance: an increasing problem? BMJ 1998 : 316:1255-1256

3. Del Mar C, Glasziou P, Hayem M. Ar antibiotics indicated as initial treatment for children with acute otitis media? A meta-analysis BMJ 1997; 314:1526-1529

4. Comité Nacional de Infectología y Comité de Pediatría Ambulatoria. Consenso sobre infecciones en pediatría ambulatoria. (Taller No2 Otitis Media, coordinado por Gentile A y Sverdloff H.)

Disponible en URL: http://www.sap.org.ar/coniambo.htm\#int

5. Feigin R, Kline M, Hyatt S, et al. Otitis Media. En: Feigin-Cherry editores. Tratado de Infecciones en Pediatría. 3ra edición Interamericana-McGraw-Hill: 1995; 197-213

6. Heikkinen T, Ruuskanen 0, Waris M, et al. Influenza vaccination in the prevention of acute otitis media in children. AJDC 1991; 145:445-448

7. Belshe R, Mendelman P, Treanor J, et al. The efficacy of live attenuated, cold adapted, trivalent, intranasal influenzavirus vaccine in children. N Engl J Med 1998;338:1405-1412 